\title{
LETRAMENTO LITERÁRIO E MEDIAÇÃO DE LEITURA: uma proposta a partir do conto O cavalo imaginário, de Moacyr Scliar

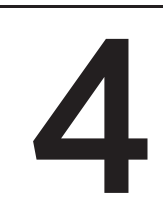

\section{LITERARY LITERACY AND READING \\ MEDIATION: a proposal using the tale O \\ cavalo Imaginário, by Moacyr Scliar}

SOUSA, Leydiane Maria

Especialista em Ensino de Literatura e outras Linguagens pela Universidade Estadual do Piauí UESPI.

E-mail: sousa.leydiane68@gmail.com

ORCID: https://orcid.org/0000-0002-5880-8059

\section{ASSIS, Emanoel Cesar Pires}

Doutor em Literatura pela Universidade Federal de Santa Catarina - UFSC.

Docente Permanente do Programa de Pós-graduação em Letras da Universidade Estadual do

Maranhão - UEMA.

E-mail: emanoel.uema@gmail.com

ORCID: https://orcid.org/0000-0001-7377-8540

\section{RESUMO:}

Nos últimos anos, multiplicaram-se as pesquisas sobre a formação do leitor de literatura. A escola, sendo o espaço natural de aprendizagem e descoberta da leitura literária, tem se tornado objeto preferencial dessas investigações. Afinal, formar leitores de literatura requer uma educação literária, e esta, por sua vez, exige um processo de ensino-aprendizagem que somente acontece no espaço escolar. Nesse sentido, este trabalho inscreve-se no campo dessas descobertas, propondo algumas reflexões. Inicialmente, buscou-se refletir sobre o letramento literário e a mediação de leitura enquanto processos que procuram promover práticas leitoras no sentido de orientar essa formação do leitor; posteriormente, refletiu-se sobre alternativas metodológicas que buscam guiar as atividades de leitura do texto em sala de aula. Nesse sentido, a proposta deste artigo consiste em promover um diálogo entre a sequência básica de Cosson (2016) e as estratégias de leitura propostas por Girotto e Souza (2011), sendo a metodologia desses pesquisadores aplicada à leitura do conto $\mathrm{O}$ cavalo imaginário, do escritor Moacyr Scliar; leitura esta que pode 
ser apresentada em turmas de $8^{\circ} \mathrm{e} / \mathrm{ou} 9^{\circ}$ anos. Dessa forma, concluiuse que, no espaço escolar, é preciso tanto mediar quanto ensinar a leitura literária, propagando o prazer e a aprendizagem; mas esta, por sua vez, só ocorre quando a abordagem do texto de literatura é feita por meio de estratégias efetivas e sistematizadas que levem o aluno a compreender que a literatura se faz linguagem.

Palavras-chave: Formação do leitor de literatura; letramento literário; mediação de leitura; estratégias de leitura.

\section{ABSTRACT:}

In recent years, researches on the formation of the literature reader have multiplied. The school, being the natural space for learning and discovering literary reading, has become the preferred object of these investigations. After all, training readers of literature requires literary education, which in turn requires a teaching-learning process that only happens in the school space. In this sense, this work fits in the field of these discoveries, proposing some reflections. Initially, we sought to reflect on literary literacy and reading mediation as processes that seek to promote reading practices in order to guide this formation of the reader; later, it was reflected on methodological alternatives that seek to guide the activities of reading the text in the classroom. In this sense, the purpose of this article is to promote a dialogue between the basic sequence of Cosson (2016) and the reading strategies proposed by Girotto and Souza (2011), the methodology of these researchers was applied to the reading of the tale $\mathrm{O}$ Cavalao Imaginário, by Moacyr Scliar; This reading can be presented in 8th and / or 9th grade classes. Thus, it was concluded that, in the school space, it is necessary to mediate as well as to teach literary reading, propagating pleasure and learning; but this, in turn, only occurs when the approach of the literature text is made through effective and systematized strategies that lead the student to understand that literature is language in use.

Keywords: Formation of the literature reader; literary literacy; reading mediation; reading strategies. 


\section{INTRODUÇÃO}

O contato entre leitores e literatura ocorre em diversos meios e de diversas formas. Ele se realiza tanto em espaços presenciais quanto em espaços virtuais; materializando-se na família, na biblioteca (da escola, da universidade, da comunidade), no grupo de leitura; nas redes sociais voltadas exclusivamente para leitores ${ }^{1}$, onde é possível escolher e discutir com autonomia os textos a serem lidos. Além disso, essa aproximação ocorre por meio de diferentes manifestações literárias, pois essas se apresentam também em outras formas de arte e em outros tantos suportes e meios que não apenas o escrito. No entanto, apenas esse contato, por vezes um tanto superficial, não é suficiente para a formação do leitor de literatura, este é formado por meio de uma educação literária, e esta, por sua vez, requer um processo de ensinoaprendizagem que somente acontece na escola. Desse modo, é por isso que o trabalho com a literatura feito no espaço escolar destacase entre as pesquisas sobre o fenômeno da leitura literária, recaindo especial atenção ao trabalho desenvolvido pelo professor; afinal, é sobre ele que incide a responsabilidade por promover o encontro entre alunos e literatura, sendo o seu papel fundamental para a formação do leitor literário.

Refletir sobre letramento literário e mediação de leitura fazse relevante uma vez que ambos os processos visam a formação do leitor e, atualmente, suas práticas têm sido defendidas na escola para o alcance dessa finalidade. Sabe-se que a escola representa o espaço privilegiado para a aprendizagem, a descoberta e o prazer da leitura, sendo, portanto, necessária e urgente a construção de formas diversificadas, criativas e eficazes para não apenas se ensinar a ler, mas formar leitores na escola. É nesse contexto que as práticas leitoras resultantes desses processos se tornam relevantes dentro do espaço escolar. No entanto, letrar literariamente e mediar leitura guardam algumas diferenças; enquanto o primeiro torna o aluno consciente de que a literatura também é um uso social da linguagem, e que esta exige aprendizagem; o segundo é marcado por práticas leitoras que objetivam revelar o prazer que advém do ato de ler. Nesse sentido,

1 Como exemplos dessas redes sociais, pode-se citar: Livreto, Orelha de livro, Skoob, Livralivro, entre outras, em que os usuários podem classificar os livros lidos, marcar suas próximas leituras e interagir, trocando opiniões sobre as obras lidas. 
entende-se, aqui, que é possível mediar e ensinar a leitura da literatura na escola, desenvolvendo o prazer e a aprendizagem.

Mas, para a mediação e o ensino da leitura literária tornarem-se realidade na escola, a reflexão sobre a melhor maneira de trabalhar com o texto em sala de aula é fundamental. Detendo o texto literário suas particularidades, as atividades de leitura que o envolvem precisam explorá-lo de modo que o aluno se torne consciente dessa singularidade. O discente precisa compreender que dominar a leitura da literatura significa dominar um universo que se faz linguagem; por isso cabe a reflexão sobre formas diversificadas de abordagem do texto. Assim sendo, muitos pesquisadores da área têm proposto metodologias alternativas, como Cosson (2016) e Girotto e Souza (2011), cujas pesquisas propõem formas efetivas e sistematizadas de lidar com o texto. O primeiro oferece como alternativa uma sequência (a básica, para o Ensino Fundamental, e a expandida, para o Ensino Médio) com etapas distintas; já as pesquisadoras apresentam estratégias de leitura. Embora suas metodologias sejam diferentes, elas se encontram em alguns pontos. Ambos os estudiosos, por exemplo, defendem o momento da leitura; e, aqui, acredita-se ser a etapa em que se deve privilegiar o uso das estratégias de leitura para enfocar o texto, mostrando suas particularidades.

Dessa forma, para a atividade de leitura literária a partir do diálogo entre a sequência básica de Cosson (2016) e as estratégias de leitura de Girotto e Souza (2011), escolheu-se o conto O cavalo imaginário, do escritor gaúcho Moacyr Scliar. A escolha por esse gênero deve-se ao fato de que os contos são narrativas curtas, indo ao encontro, portanto, da prática de leitura em sala de aula, uma vez que sua análise não exige muitas horas; e da preferência dos jovens, que, fora da escola, têm dado destaque a essas narrativas. Já a opção por esse conto em particular, considerou o fato de que, por meio dele, foi possível aplicar as estratégias de leitura de forma a potencializar o seu uso e desvendar as múltiplas leituras que a literatura oferece. Assim, a atividade de leitura oferecida no espaço deste artigo pode ser aplicada em turmas de $8^{\circ}$ e/ou $9^{\circ}$ anos, pois, nessas séries, os alunos já são leitores críticos, isto é, aqueles leitores que têm capacidade de lidar com todas as estratégias de leitura, refletindo sobre seu uso e importância para a compreensão das múltiplas leituras que o texto de literatura oferece. 
Deseja-se, assim, com este trabalho, traçar um caminho de reflexões e práticas no qual o docente comprometido com o ensinoaprendizagem de seus alunos possa trilhar, para que ele vislumbre ser possível sim formar leitores de literatura na escola. Estes, por sua vez, poderão sair desse espaço munidos do conhecimento necessário para transitar em outros lugares, sejam reais ou virtuais, onde eles também se encontram com o texto de literatura. Almeja-se, em resumo, com este estudo, poder contribuir para promover o ensino da leitura literária na escola, com vistas à formação e desenvolvimento do leitor de literatura: leitor autônomo, capaz de selecionar suas leituras, de ler movido pelo prazer estético proporcionado pela especificidade da linguagem literária, produzindo sentidos no diálogo com o texto, e entendendo que esse universo que se faz linguagem é imprescindível para sua formação humana e social.

\section{A FORMAÇÃO DO LEITOR DE LITERATURA: LETRAMENTO LITERÁRIO OU MEDIAÇÃO DE LEITURA?}

Segundo Cosson e Souza (2011), o letramento literário faz parte da expansão do uso do termo letramento, integrando o plural dos letramentos, sendo, portanto, um dos usos sociais da escrita. No entanto, o letramento literário consiste em uma prática única, pois usase a linguagem escrita na construção de um universo ora narrativo ora poético, isto é, na construção da literatura, e esta, por sua vez, "ocupa um lugar único em relação à linguagem" (COSSON; SOUZA, 2011, p. 102). Como afirma Cosson:

A literatura não apenas tem a palavra em sua constituição material, como também a escrita é seu veículo predominante. A prática da literatura, seja pela leitura, seja pela escritura, consiste exatamente em uma exploração das potencialidades da linguagem, da palavra e da escrita, que não tem paralelo em outra atividade humana (COSSON, 2016, p. 16).

Nesse sentido, a literatura faz-se linguagem, sendo um exercício de exploração das palavras em que se busca, por meio delas, construir sentidos múltiplos, seja pela tessitura ficcional das narrativas ou pelo arranjo sonoro, visual da poesia. Assim, o letramento literário consiste em um uso individual, mas também social da linguagem escrita. Dessa forma, como afirmam Cosson e Souza (2011, p. 102), "o letramento feito com textos literários proporciona um modo privilegiado de inserção 
no mundo da escrita, posto que conduz ao domínio da palavra a partir dela mesma". Assim, letrar literariamente corresponde a proporcionar a experimentação da palavra escrita por ela mesma, isto é, adentra-se um universo feito linguagem pela própria linguagem.

Além disso, observa-se que o letramento realizado com textos de literatura, conforme ressalta Pinheiro (2006 apud VIEIRA, 2015, p. 121), "de um modo geral, acaba envolvendo somente o fenômeno da leitura. As habilidades de escrita literária não costumam ser cobradas dos indivíduos, uma vez que são concebidas como escolhas individuais". Dessa maneira, o letramento literário se efetiva na leitura, uma vez que a prática de escrita literária ainda não é muito incentivada em espaços sociais diversos em que a literatura esteja presente. Esse tipo de leitura, por sua vez, encontra no espaço privilegiado da escola seu efetivo exercício, pois "o letramento literário precisa da escola para se concretizar, isto é, ele demanda um processo educativo específico que a mera prática de leitura de textos literários não consegue sozinha efetivar" (COSSON; SOUZA, 2011, p. 102). Entende-se, dessa maneira, que a escola é a instituição que orienta o aluno-leitor no entendimento de que ler literatura é mais do que realizar leituras diversas, é também entender como se constrói esse universo feito linguagem.

Nesse sentido, considerando o letramento literário como o processo de apropriação da linguagem literária que se realiza na leitura e na escola, é que se faz relevante destacar a finalidade de letrar literariamente o aluno. O objetivo do letramento literário consiste na formação do leitor, mais especificamente na formação do leitor de literatura. A educação literária que ocorre no espaço escolar deve visar à formação e ao desenvolvimento do leitor literário, este pode ser entendido como o indivíduo capaz de "não apenas [...] ler e compreender gêneros literários, mas [que] aprendeu a gostar de ler literatura e o faz por escolha, pela descoberta de uma experiência de leitura distinta, associada ao prazer estético (BARBOSA, 2011, p. 148). Para Paulino e Pinheiro (2004 apud SILVA 2015, p. 23):

A formação de um leitor literário significa a formação de um leitor que saiba escolher suas leituras, que aprecie construções e significações verbais de cunho artístico, que faça disso parte de seus fazeres e prazeres. Esse leitor tem de saber usar estratégias de leitura adequadas aos textos literários, aceitando o pacto ficcional proposto, com reconhecimento de marcas linguísticas de subjetividade, 
intertextualidade, interdiscursividade, recuperando a criação de linguagem realizada [...].

Assim, letrar literariamente o aluno na escola significa formar leitores autônomos, leitores que sabem fazer suas escolhas dentro de um vasto rol de textos, que compreendam a especificidade das manifestações literárias, sua linguagem artística, que apreciem tal linguagem, que saibam usar as estratégias adequadas para abordar o texto e, por fim, reconheçam a importância do texto de literatura na sua formação não somente enquanto leitor, mas também enquanto sujeito reflexivo, criativo e crítico.

Desse desejo de formar leitores, seja no espaço da escola, seja em outros espaços sociais, nasce a busca por caminhos atrativos, por metodologias inovadoras que oportunizem aos alunos e a outros sujeitos o encontro com o texto e a, consequente, formação leitora. Um desses caminhos, que muito se debate atualmente, é representado pela noção de mediação de leitura. Cosson (2015), em A prática da leitura literária na escola: mediação ou ensino?, mostra a relevância desse tema apontando a oferta de cursos voltados para a formação de professores mediadores e trabalhos acadêmicos produzidos nos últimos anos que tiveram como ponto de partida o tema da mediação de leitura. Ele observa que "são diversos os agentes, as propostas e as posições metodológicas e teóricas que alimentam os estudos acadêmicos, os cursos, as oficinas, as capacitações e as próprias atividades dentro e fora da escola envolvendo a mediação de leitura" (COSSON, 2015, p. 163).

A mediação de leitura, por sua vez, consiste em práticas que visam, inicialmente, colocar o leitor em contato com o livro, ou seja, possibilitar o acesso ao livro. Além disso, as práticas leitoras na mediação de leitura são construídas a partir da ideia de promoção do encontro entre leitor e texto; esse encontro, por sua vez, ocorre por meio do diálogo, da liberdade, da autonomia, do respeito à realidade, às experiências vividas, interesses e expectativas dos sujeitos envolvidos. Em outras palavras, mediar a leitura significa um convite a um exercício dialógico proporcionado pela leitura, sobre a leitura e sujeitos envolvidos nessa prática. Conforme Lima (2018, p. 7):

A mediação da leitura caracteriza-se pelas relações dialógicas entre os sujeitos, o texto mediado e o ato mediador. É um diálogo constituído de múltiplas vozes 
e narrativas, de natureza dinâmica, flexível e crítica. Em forma de diálogo, a mediação pode ocorrer em diferentes formatos para públicos diversos em [diversas] ambiências [...] Na dialogicidade da mediação da leitura para conectar pessoas e textos [...].

Nesse processo dialógico, cabe a um mediador a responsabilidade pelo desenvolvimento das tarefas de mediação, isto é, o mediador é o indivíduo responsável por proporcionar o acesso ao livro, por promover o encontro entre leitor e texto e por mediar o diálogo entre os sujeitos envolvidos nas práticas leitoras. Ainda segundo Lima (2018), um mediador de leitura:

a) Inicialmente, deve tratar-se de um(a) leitor(a), alguém que gosta de ler. É um(a) leitor(a) crítico(a), cujas experiências são partilhadas no processo de interação com o outro;

b) Além da experiência de leitura, é necessário gostar de comunicar-se, de falar do que lê, compartilhar seus repertórios e afetividade;

c) Percebe na mediação a possibilidade de mudança a ser realizada no cotidiano das pessoas, de modo que compreendam o espaço que a leitura ocupa em suas vidas;

d) Compreende as diferentes fases pelas quais um leitor se constrói e se torna íntimo da leitura, sem exigências, deixando fluir, sem estabelecer juízos (LIMA, 2018, p. 9).

Assim, um mediador de leitura precisa ser dotado dessas características; para ser mediador, precisa ser também leitor, mais que isso, precisa gostar de ler, de interagir, de partilhar leituras, sem juízos pré-estabelecidos, ser capaz, portanto, de promover o diálogo, aceitando as interpretações dos sujeitos envolvidos. O mediador é aquele leitor encantado com as histórias que leu e das quais se apropriou, fazendo delas parte de si, só assim, também conseguirá encantar o outro, mostrando a ele o prazer que advém da leitura; é aquele que objetiva oportunizar um encontro prazeroso, sem cobranças, entre leitores e texto literário.

Nesse sentido, diante do exposto, é que se tem defendido a presença da mediação de leitura e de professores mediadores na escola. Cosson (2015) observa que a mediação de leitura literária está associada a práticas de lazer, de fruição e deleite, cujo objetivo é levar o aluno a ler diversificadamente e com prazer, destinando ao professor o papel de facilitador do acesso ao livro, desenvolvendo o hábito de 
ler tanto na escola como fora dela. Ele ressalta, porém, que, embora as ideias relacionadas à mediação de leitura e professor mediador venham ao encontro das demandas de estudiosos do letramento literário, tais como a autonomia do leitor, a necessidade do professor também ser leitor de literatura, a formação do leitor e o encontro entre leitor e texto, essa prática parece recusar à escola e ao professor a função de ensinar. O pesquisador observa que é preciso compreender o papel do professor e da escola como responsáveis pelo ensino.

Não se pode negar ao professor o lugar de conhecimento, planejamento e execução do ensinar que é próprio de sua atuação. Assim como que não se pode advogar um ensino que ignore a condição de sujeito do aluno e o processo de interação que é o ensinar e o aprender na sala de aula (COSSON, 2015, p 169).

Nesse sentido, o autor questiona a mediação de leitura literária na escola, observando que as práticas leitoras desenvolvidas nessa mediação, embora possam representar a satisfação de antigas demandas do letramento literário, resultam no esvaziamento da função do professor. Além disso, esquece-se, às vezes, o fato de que a linguagem literária exige, sim, um processo de ensino-aprendizagem. Como ressalta Cosson (2010), a linguagem literária não dispensa a aprendizagem; "a leitura literária implica códigos, protocolos, práticas e convenções que identificam o que é literatura e informam sobre os diversos modos de ler o texto literário" (COSSON, 2015, p. 169). Ele acredita, porém, que a mediação de leitura literária não pode ser reduzida à ideia de que seja uma prática voltada apenas ao incentivo do ato de ler literatura por meio de um professor mediador apaixonado por esse ato, dispensando, assim, uma formação específica. Dessa forma, o ensino de literatura na escola não pode ser igualmente reduzido à ideia de que seu objetivo é proporcionar o prazer de ler.

Dessa maneira, entende-se a importância da mediação de leitura e do professor mediador na escola, já que suas práticas leitoras almejam igualmente promover a formação do leitor de literatura por meio de atividades que despertem o prazer no ato de ler e o encontro, a conexão entre texto e leitor. No entanto, acredita-se que a verdadeira experimentação da literatura e da leitura ocorre quando o leitor, mais que encontrar satisfação e deleite nesse exercício, compreende que a literatura se faz linguagem, que ela possui características próprias que se manifestam na construção de sua materialidade linguística. 
Essa experimentação só acontece, assim, quando o professor, além de mediar, ensina como adentrar esse universo literário.

Por isso, faz-se necessário que o professor seja, sim, leitor experiente, com rico repertório de leituras, bem como possua domínio da esfera literária e formação e conhecimento sobre a melhor maneira de se trabalhar com o texto em sala de aula. Nesse aspecto, é que se considera de grande relevância a pesquisa e o conhecimento sobre alternativas metodológicas que buscam orientar as atividades de leitura e de abordagem do texto literário. A utilização da metodologia e de estratégias efetivas e sistematizadas de leitura permite levar o aluno a adentrar e compreender a linguagem literária e sua especificidade; permite, assim, ensinar a ler literatura. Dessa forma, almeja-se uma abordagem da literatura na escola que tanto ensina quanto media o encontro do leitor com o texto de literatura.

\section{ALTERNATIVAS METODOLÓGICAS: APRENDENDO A LER LITERATURA}

O leitor literário competente, pode-se dizer, é aquele capaz de selecionar suas leituras ao se deparar com um vasto rol de textos literários. Essa seleção, por sua vez, será ancorada na certeza de que o texto escolhido, além de lhe proporcionar um prazer estético singular, não lhe devolverá ao mundo da mesma forma, isto é, o leitor não mais será o mesmo após a leitura. É esse tipo de leitor que as práticas leitoras promovidas na escola devem almejar formar: um indivíduo consciente da importância da literatura para a sua vida. Assim sendo, a formação desse leitor competente passa pela reflexão sobre qual a melhor maneira de trabalhar com o literário no espaço da sala de aula, sobre formas efetivas de garantir o ensino da leitura literária.

A busca por alternativas tem sido objeto de pesquisa de muitos estudiosos da área, como Valarini (2012) que destaca a importância de uma proposta metodológica para o ensino da leitura do texto literário, observando o uso de estratégias de leitura. Essas estratégias, segundo a autora, devem objetivar fazer com que o aluno interaja com o texto e perceba neste as possibilidades de (re)conhecimento do mundo que tal texto propõe. Além disso, esse uso desenvolve o gosto pelo literário e o potencial reflexivo e crítico necessário para o desenvolvimento do gosto e refinamento estético. A pesquisadora observa também que esse ensino de estratégias é uma proposta coerente já que, em uma aula de leitura em que o objeto de estudo é o texto literário, o professor precisa 
destacar para seus alunos que o texto requer estratégias diferentes para a sua compreensão.

Assim, as estratégias de leitura se mostram relevantes uma vez que elas permitirão abordar o texto, abrindo caminhos possíveis por onde o leitor possa caminhar com confiança e encontrar-se, desse modo, com o texto numa atividade de leitura significativa e de construção de sentidos. Dessa forma, detalha-se aqui algumas estratégias de compreensão leitora (que podem ser usadas para abordar o texto de literatura), seguindo o percurso proposto por Girotto e Souza (2011), cuja pesquisa buscou introduzir algumas estratégias de leitura como alternativa metodológica para a educação literária. Essa alternativa metodológica, por sua vez, baseou-se em "uma metodologia norteamericana que tem suas origens nos estudos da metacognição" (GIROTTO e SOUZA, 2011, p. 4). A metacognição é:

o conhecimento sobre o processo de pensar, que leva à compreensão do texto, sendo duas as maneiras de entender o que se lê: a primeira ocorre no plano do aqui e agora, e o leitor de um texto o lê frase por frase, palavra por palavra até o final. [...] A segunda maneira, conquistada a longo prazo pelo leitor, ocorre quando ele utiliza seu conhecimento para compreender as estratégias que o fizeram entender o que leu (PRESSLEY, 2002 apud GIROTTO E SOUZA, 2011, p. 5).

Assim, traçar um conjunto de estratégias de leitura, a partir dessa metodologia, consiste em levar o aluno a compreender as estratégias que ele utiliza para entender o texto. Conforme Rodrigues (2018, p. 116), as estratégias de leitura podem ser compreendidas como "procedimentos conscientes (metacognitivos) dos quais o leitor se vale no ato da leitura para, de modo intencional, construir sentidos". Dessa forma, ao propor uma atividade de leitura em sala de aula, o professor precisa não somente considerar o aluno/leitor sujeito ativo no processo, mas também mostrar a esse aluno seu papel enquanto agente atuante ao realizar leituras. Em outras palavras, ensinar leitura significa demonstrar ao discente que ele interage e dialoga com o texto e seu contexto.

Daí a relevância da utilização dessa metodologia, pois evidencia para o aluno/leitor como sua mente funciona enquanto lê, e quais estratégias ele utiliza no entendimento dessa leitura. Segundo as autoras, "quando falamos em formar bons leitores estamos nos 
referindo àqueles que, conscientemente, utilizam as estratégias de leitura quando leem" (GIROTTO e SOUZA, 2011, p. 5). Nesse aspecto, elas defendem um ensino reflexivo/explícito, base para o processo de ensino-aprendizagem das estratégias de compreensão leitora, isto é, um ensino que torne transparente ao aluno os processos mentais que ele realiza ao ler, levando-o à reflexão sobre tais processos e sobre o papel ativo que ele desempenha nessa construção.

Dessa maneira, Girotto e Souza (2011) mencionam quatro aspectos essenciais que devem ser observados pelo professor na sua prática ao mediar o ensino da leitura literária por meio das estratégias de leitura. Primeiramente, a definição da estratégia a ser utilizada, determinando sua utilidade para a compreensão do texto literário escolhido. O segundo aspecto diz respeito a tornar o processo transparente, isto é, o ensino de uma estratégia de leitura pressupõe a explicação verbal daquilo que se passa na mente de um leitor durante o ato de ler. Em terceiro lugar, é importante que o docente interaja com os alunos, orientando-os no intuito de levá-los ao domínio da estratégia escolhida e utilizada na abordagem do texto. Para tanto, as pesquisadoras destacam que momentos da aula devem ser reservados para a condução desse trabalho, promovendo um diálogo em que o professor ilustra o modo ideal de utilização da estratégia com vistas à autonomia do educando que, fora da escola, vai ser capaz de escolher suas leituras de acordo com seus objetivos e de selecionar as melhores estratégias para abordar o literário, construindo um diálogo com o texto e produzindo sentidos.

É nesse contexto que as pesquisadoras propõem uma sequência didática em que o professor irá trabalhar com aquilo que elas denominam de Oficina de leitura: momentos específicos em sala de aula em que o docente planeja o ensino das estratégias de leitura. As autoras sugerem que a oficina tenha início com o professor lendo em voz alta e mostrando como leitores pensam enquanto leem; em outras palavras, o professor deve explicitar o diálogo que o leitor mantém com a obra. Construindo sentidos ao fazer perguntas, conexões, inferências e ativando conhecimentos e vivências anteriores. Desse modo, as autoras destacam as sete habilidades ou estratégias de leitura de acordo com Pressley (2002): conhecimento prévio, conexão, inferência, visualização, perguntas ao texto, sumarização e síntese.

Conforme Silva (2019), essa metodologia considera três 
momentos: moldar, prática guiada e prática individual. No primeiro momento, o professor molda o ato de ler; ele escolhe um texto e realiza a leitura em voz alta, fazendo interrupções planejadas ao perceber uma habilidade de leitura, exemplificando-a aos alunos. O segundo momento, de prática guiada, é usado para repetir a estratégia, mas dessa vez com a participação dos alunos. Cabe ressaltar, conforme Girotto e Souza (2011), que, quando se lê, todas as estratégias de leitura são colocadas em ação sem uma ordem específica, mas, ao ensinálas, o professor precisa agir didaticamente, explicitando o processo. O terceiro momento, de prática individual, consiste no período em que o aluno, ao ler sozinho um texto, registra a estratégia ao utilizá-la mentalmente. Nesse último momento, o aluno torna-se autônomo em sua leitura e consciente das estratégias utilizadas para a compreensão do texto, entendendo, assim, que ele é sujeito leitor ativo na construção dos sentidos.

Antes da definição de cada estratégia acima mencionada, considera-se relevante explicitar, agora, algumas ideias-chave de Cosson (2016). Para ele, o processo de leitura obedece às seguintes etapas: a antecipação, a decifração e a interpretação. A primeira delas consiste nas várias operações que o leitor realiza antes de adentrar o texto propriamente, ou seja, o leitor, inicialmente, lê a capa, o número de páginas, o título da obra. Dessa forma, nessa primeira leitura, ele já começa a formular suas hipóteses acerca da obra a ser lida. A segunda etapa diz respeito à leitura feita palavra por palavra, isto é, a decodificação. A terceira e última etapa, a interpretação, resulta das "relações estabelecidas pelo leitor quando processa o texto. O centro desse processamento são as inferências que levam o leitor a entretecer as palavras com o conhecimento que tem do mundo. Por meio da interpretação, o leitor negocia o sentido do texto [...]" (COSSON, 2016, p. 40-41).

Nesse sentido, considerando essas etapas, Cosson (2016) estabelece sua metodologia, propondo uma sequência básica² e situando quatro momentos essenciais, a saber: a motivação, a introdução, a leitura e a interpretação. O primeiro consiste em trabalhar

2 Cosson (2016) sistematiza as aulas de literatura em duas sequências exemplares: uma básica e a outra expandida. Esta é destinada a atividades a serem realizadas no ensino médio, enquanto aquela no ensino fundamental. A sequência expandida segue as mesmas etapas da sequência básica (motivação, introdução, leitura e interpretação) com a diferença de que nesta há dois momentos destinados à interpretação. Como este trabalho visa propor uma atividade de leitura para o ensino fundamental, optou-se por discorrer sobre a sequência básica. 
a antecipação, ou seja, explorar as hipóteses levantadas a partir da leitura dos elementos pré-textuais e convidar o leitor para a leitura do texto. O segundo momento, a introdução, é a etapa que se destina à apresentação do autor e da obra a ser lida. A etapa da leitura, por sua vez, refere-se ao momento da leitura do texto, sendo acompanhada de perto pelo professor, que fica atento às dificuldades enfrentadas pelos alunos. Já o momento da interpretação é a fase de construção de sentidos em um diálogo entre leitores, texto e comunidade. A interpretação divide-se em dois momentos: a fase da leitura, momento do encontro entre leitor e texto, e a fase da sua materialização, compartilhada pela comunidade de leitores.

Dessa forma, a etapa da antecipação como elaborada por Cosson (2016) coincide com a motivação, isto quer dizer que o aluno precisa ser convidado a adentrar no texto, e, nesse convite, já se inicia o processo de leitura, pois o aluno, como referido acima, lê inicialmente o título do texto, sua extensão; e, nessa leitura, começa a formular suas hipóteses que podem ser confirmadas ou não à medida que avança no texto. É importante, assim, o professor iniciar o processo de leitura, com uma atividade de motivação, fazendo com que os alunos levantem hipóteses sobre o que vai ser lido, uma vez que as "hipóteses [são] baseadas no conhecimento prévio do leitor [...] Tais hipóteses representam o começo da compreensão dos significados do texto e serão confirmadas durante a leitura do livro" (GIROTTO; SOUZA, 2011, p. 14).

Assim, o conhecimento prévio é a primeira estratégia a ser acionada, e, conforme as pesquisadoras, é a estratégia que, a todo momento, o leitor ativa, acionando conhecimentos que já possui em relação ao texto lido, em relação às suas ideias, e que ajudarão na compreensão e construção dos sentidos do texto. Após a atividade de motivação, o professor inicia a introdução, apresentando o autor, permitindo que os alunos conheçam um pouco sobre ele e sobre a obra escolhida. Em seguida, tem início a leitura, ou seja, leitura do texto até seu término e apreensão do sentido global da obra lida. Essa etapa precisa ser acompanhada pelo professor, conferindo o andamento da leitura dos alunos, bem como precisa ser um momento de diálogo e análise, de resolução de problemas de vocabulário e da estrutura do texto. É na etapa da leitura que se apresenta aos alunos, assim, as outras estratégias. 
Nesse sentido, tem-se a estratégia de conexão (que também está ligada ao conhecimento prévio), pois a leitura permite a realização de conexões com outros textos conhecidos, com situações reais vivenciadas, conexões com a realidade e o mundo. Silva (2019) menciona: "as conexões texto-texto (leio uma palavra do livro e me lembro de outro livro), a conexão texto-leitor (leio uma palavra e me lembro de algo da minha vida) [...] Há ainda a conexão texto-mundo" (p. 26-27). A estratégia da inferência, por sua vez, "é compreendida como a conclusão ou interpretação de uma informação que não está explícita no texto, [...] uma inferência é uma suposição, ou uma oferta de informação que não está explícita no texto - algo como ler nas entrelinhas" (GIROTTO; SOUZA, 2011, p. 14).

Já a estratégia de visualização é realizada de maneira espontânea, uma vez que, ao ler o texto literário, as descrições invadem nossa mente transformando-se em imagens. As autoras destacam que essa estratégia é uma forma de inferência e, por isso, devem ser trabalhadas de maneira aproximada. Soma-se a essas a habilidade de fazer perguntas ao texto, perguntas que devem ser feitas a partir dos indícios dados pela linguagem literária; essa estratégia auxilia na compreensão do texto e na construção de sentidos por parte do leitor. Defende-se, aqui, que as estratégias de inferência, visualização e perguntas ao texto devem ser conduzidas pelo professor de forma que os alunos tanto se tornem conscientes do uso dessas habilidades e da sua importância para a compreensão do texto quanto aprendam a usá-las para explorar a potencialidade e especificidade da linguagem literária.

Por fim, tem-se a sumarização e síntese. A primeira consiste em apreender o que é essencial em um texto, apreender o que é importante na narrativa, mostrando aos alunos como essa estratégia é importante para a compreensão da história. Já a segunda ocorre quando se relaciona o lido com as próprias impressões, ou seja, reconstrói-se o texto a partir de si mesmo, acrescentando às ideias essenciais da narrativa o entendimento e conhecimentos adquiridos ao final da leitura. Desse modo, segundo ainda Girotto e Souza (2011), a última etapa da oficina de leitura é o momento da avaliação, em que se verifica se o objetivo foi alcançado, e da conversa em grupo sobre o texto lido. Essa etapa da conversa vem ao encontro do que propõe Cosson (2016), quando ele pensa o momento da interpretação como o diálogo final sobre os sentidos construídos ao longo da leitura numa comunidade de leitores. 


\section{OFICINA DE LEITURA: O CAVALO IMAGINÁRIO, DE MOACYR SCLIAR}

Considerando, primeiramente, Girotto e Souza (2011), quando destacam que é importante a definição da estratégia utilizada de acordo com sua utilidade para a compreensão do texto; e, em segundo lugar Silva (2019), quando observa que a escolha do texto precisa ser cuidadosa, pois ele deve potencializar a estratégia enfocada, escolheuse o conto $O$ cavalo imaginário, do escritor gaúcho Moacyr Scliar, pois essa narrativa permite trabalhar todas as estratégias, de modo a levar os alunos à compreensão do texto e da importância das próprias estratégias em sua abordagem. Além disso, optou-se por propor aqui uma prática guiada, ou seja, aquela etapa em que, com a participação dos alunos, o professor ensina uma determinada estratégia de leitura. Dessa forma, essa narrativa, devido à sua temática social, pode ser trabalhada com alunos do $8^{\circ} \mathrm{e} / \mathrm{ou} 9^{\circ}$ anos do Ensino Fundamental II.

O conto em questão é de fácil acesso e tem como tema as relações de poder que se estabelecem dentro de um grupo de garotos. A narrativa apresenta um grupo de meninos ricos, filhos de fazendeiros, e Francisco, filho de um simples sapateiro, mas que acaba adentrando o grupo de meninos ricos. Todos eles estudam na mesma escola, mas Francisco consegue tal façanha graças a uma bolsa de estudos. O líder do grupo é Rodrigo, jovem orgulhoso e arrogante, que aceita Francisco entre eles apenas na escola, onde este lhes presta favores e admiração; pois, no clube hípico, para onde Francisco os segue, a coisa é diferente: Rodrigo faz questão de mostrar o lugar que ele acredita ser de Francisco.

Dando início à oficina de leitura, a sugestão é começar com uma atividade de motivação, como proposta por Cosson (2016), convidando, assim, os alunos a adentrarem no texto. Essa atividade tem início com o professor perguntando aos alunos se eles aceitariam uma aposta impossível de vencer. Aqui, o docente pode usar exemplos para tornar mais clara essa atividade. No conto, Rodrigo, montado em seu belíssimo cavalo puro-sangue, aposta com Francisco, montado em seu cavalo imaginário, uma corrida, em que o perdedor seria obrigado a entregar seu cavalo. Rodrigo, assim, desafia Francisco, que, para espanto dos demais, aceita, mesmo sendo impossível vencer. Os alunos devem refletir e anotar suas respostas e justificativas, para, em seguida, serem socializadas com a turma e o professor, encerrando, assim, a motivação. 
Posteriormente, após esse momento, o professor esclarece que a pergunta feita deve-se ao fato de que eles irão ler a história de Francisco, um garoto que aceitou um desafio impossível de vencer. Então, o docente apresenta o autor do texto, o escritor gaúcho Moacyr Scliar, que se formou em medicina, mas abandonou a carreira para se dedicar à literatura, tendo escrito contos, crônicas e romances. Após esse esclarecimento, o professor volta ao texto e faz a seguinte pergunta: que tipo de garoto parece ser Francisco para aceitar um desafio insuperável? Nesse momento, os alunos levantam hipóteses que devem ser ouvidas pelo professor. Lembrando que, como afirmam Girotto e Souza (2011), as hipóteses já representam o começo da compreensão do texto, ativando o conhecimento prévio dos alunos.

Entrega-se então a cópia do conto para início da leitura partilhada, momento em que se explicita as estratégias escolhidas. Nesse sentido, o docente inicia com a turma a leitura em voz alta, parando para exemplificar as estratégias utilizadas. Primeiramente, o trabalho pode ser centrado na visualização. No primeiro parágrafo do conto, o narrador apresenta uma visão geral dos lugares e do grupo de meninos ricos, descrevendo-os. Nesse momento, o docente explicita à turma as suas visualizações, como ele imagina aqueles lugares e personagens. Em seguida, concede a palavra aos alunos, pedindo para que eles digam o que veio à mente deles. Após as respostas, ele explica a estratégia de visualização, esclarecendo que, por meio das descrições feitas no texto, as imagens de lugares, personagens ou situações preenchem a mente e que será assim durante toda a leitura. As imagens ajudam a conectar aspectos do que é narrado, isto é, a sequência narrativa. A partir daí, o professor pede aos alunos que, durante a leitura, sempre que vier uma visualização curiosa à mente, eles anotem. Conforme Girotto e Souza (2011), o leitor, ao realizar visualizações durante a leitura, vai criando imagens pessoais e isso mantém a atenção, tornando a leitura significativa.

No segundo parágrafo, a estratégia a ser enfocada é o conhecimento prévio; ressalta-se, porém, que esta habilidade, conforme as autoras, é aquela a todo momento acionada pelo leitor, aqui tornase apenas claro o seu uso. O segundo parágrafo do texto, assim, se mostra adequado para se explicitar essa estratégia, uma vez que o narrador menciona que ele e os amigos praticavam equitação, que eram excelentes ginetes. Dessa forma, independentemente da turma, 
dos sujeitos ali envolvidos, o professor mostra como o conhecimento prévio sobre esse tema é importante para a compreensão do texto, uma vez que sua caracterização é elemento usado para estabelecer a distinção entre o grupo de meninos ricos e Francisco, alimentando a tensão na narrativa. Além disso, a ausência desse conhecimento prejudica inclusive a visualização, pois não haverá elementos para entender a caracterização feita e sua importância dentro do texto.

No terceiro e quarto parágrafos, o narrador, finalmente, apresenta Francisco, caracterizando-o a partir de uma nítida oposição entre ele e seu grupo. Ao final do quarto parágrafo, o narrador indaga: mas o que [Francisco] fazia em nosso grupo? Aqui, o professor explica a estratégia de perguntas ao texto. Ele indaga se, antes da pergunta do narrador se tornar conhecida deles, eles próprios não fizeram essa pergunta. Ouvindo os comentários da turma, o docente mostra que, a partir dos indícios dados pelo texto e recuperados na materialidade da linguagem, a todo momento perguntas são feitas ao texto, o leitor questiona e se questiona; e que, ao aventar respostas possíveis, levanta-se, novamente, hipóteses sobre o que vai acontecer na história. Muitas vezes são essas hipóteses, que podem se confirmar ou não, que mantêm a expectativa sobre o que vai acontecer, mantendo, igualmente, o interesse pela história contada. Segundo Girotto e Souza (2011, p. 14), "ensinar os alunos a fazerem perguntas ao texto também auxilia a compreensão da história. Essa estratégia ajuda as crianças a aprenderem com o texto, a perceberem as pistas dadas pela narrativa".

No quinto parágrafo, pode-se trabalhar ainda as perguntas ao texto e a estratégia de inferência. Nesse parágrafo, o narrador descreve como se caracteriza a relação entre Francisco e seu grupo de amigos ricos, cujo líder era Rodrigo. O grupo do narrador é detestado pelos outros meninos da escola, mas Francisco os admirava, fazendo favores impensáveis para eles. A partir da leitura desse parágrafo, o professor solicita aos alunos que eles anotem todas as perguntas que surgiram da leitura. Em seguida, todos devem ler os questionamentos feitos e aventarem respostas possíveis para suas próprias perguntas e perguntas dos demais.

Já a inferência pode ser trabalhada conjuntamente às perguntas feitas ao texto. O professor mostra, então, a relação entre elas, uma vez que os questionamentos ajudam a ler as entrelinhas, ou seja, aquilo que não está explícito no texto. Assim, por meio das perguntas, 
pode-se obter a seguinte leitura: Francisco admirava os meninos do grupo porque talvez desejasse ser como eles, fazia-lhes favores para ser aceito, eles não gostavam de Francisco no clube porque talvez lá ele os envergonhava, já que não tinha cavalo e não podia, assim, se misturar. Estas são algumas leituras possíveis que nascem das perguntas e se configuram como a leitura das entrelinhas, isto é, são inferências. Segundo Girotto e Souza (2011), as inferências levam o leitor a entender as inúmeras facetas do que está lendo. Cabe, assim, ao docente tornar transparente essas estratégias e sua importância para a compreensão do texto, mostrando aos alunos que assim eles estão construindo sentidos.

No sexto e sétimo parágrafos, o narrador esclarece que Rodrigo não gostava da atitude de Francisco no clube e que ele, Rodrigo, era um garoto desagradável, intratável, agressivo, somente tolerado pelo demais porque era filho do maior fazendeiro da região e prefeito da cidade. Nesse parágrafo, o professor pode abordar a conexão textoleitor, ou seja, conexão que, conforme Silva (2019), o leitor estabelece diretamente a partir de sua vida e experiência. Ele pergunta à turma se conhece alguém, dentro ou fora da escola, com uma personalidade tão difícil quanto a de Rodrigo. Então, ele explica a estratégia acionada, mostrando que esta também está diretamente relacionada ao conhecimento prévio, e indaga ainda quais outras conexões a turma pode estabelecer.

Aqui também se pode abordar novamente a estratégia de pergunta ao texto e inferência. O docente mostra uma pergunta que ele tenha feito ao texto e que o levou à seguinte leitura: assim como Francisco se submete ao grupo para ser aceito, os demais se submetem a Rodrigo, revelando que, independentemente do grupo social, indivíduos tendem a se submeter àquele que detém mais poder no grupo, isto é, todos estão envolvidos em jogos e relações de poder. Destaca-se aqui que a inferência é a estratégia que precisa da intervenção do professor, pois ele, enquanto leitor experiente, conduz o aluno nesse exercício, mostrando a ele aquilo que pode passar despercebido a leitores iniciantes e em fase de aprendizagem. A inferência depende ainda, ressalta-se, de que os alunos sejam conduzidos pela materialidade da linguagem literária, o docente, leitor autônomo, mostra a importância dessa habilidade para a compreensão do texto de literatura, cujos sentidos se encontram também no que não é dito. 
Do oitavo ao vigésimo quinto parágrafo, novamente se pode focar na estratégia de visualização, pois é o momento de maior tensão na narrativa, seu clímax, é o momento da aposta entre Rodrigo e Francisco. O professor pede para que os alunos descrevam a cena narrada como eles imaginaram: quais seriam as expressões de Rodrigo, Francisco e do próprio narrador e do grupo? quais seus sentimentos, dos personagens e dos alunos? Ele, então, observa que a estratégia de visualização depende também dos indícios que estão no texto. O narrador dá a entender que Rodrigo está furioso, que ele, o próprio narrador, irrita-se com Rodrigo, que Francisco está, a princípio hesitante, mas depois se mostra confiante, tudo isso só é possível por meio das pistas dadas pelo texto. Aqui também se levanta hipóteses, cria-se expectativas, pois o texto sugere que Francisco possa ganhar a aposta, mantendo, assim, o interesse na narrativa.

Finalmente, ao término da leitura, aborda-se as estratégias de sumarização e síntese. A primeira, como visto anteriormente, e conforme Girotto e Souza (2011), consiste em apreender o que é essencial em um texto. Dessa forma, propõe-se que o professor esclareça ao aluno que o conto de Scliar pode ser dividido em seis partes: a primeira corresponde à apresentação do grupo de garotos ricos, do qual faz parte Rodrigo e o narrador; a segunda refere-se à apresentação de Francisco; a terceira, à caracterização das relações estabelecidas entre Francisco e o grupo; a quarta, à apresentação de Rodrigo; a quinta, é o momento da aposta; e, por fim, o desfecho da história de Francisco, com sua ida para longe da cidade e incerteza quanto ao seu destino. Dessa forma, o professor pede para que os alunos identifiquem essas partes, procurando sintetizá-las por meio de subtítulos, realizando, assim, a estratégia de sumarização.

Já a estratégia de síntese, que consiste, de acordo com as pesquisadoras, em articular o lido com as impressões pessoais do leitor, aproxima-se da noção de interpretação como moldada por Cosson (2016), para quem os sentidos construídos individualmente devem ser compartilhados pela comunidade de leitores. Assim, propõe-se que, ao final da leitura, o docente conduza um debate com os alunos sobre o tema abordado no conto. O docente pode orientar pesquisas sobre o tema e que subsidiarão o debate, direcionando os alunos para a descoberta de histórias parecidas com a de Francisco e das consequências de relações como a abordada no conto na vida das 
pessoas. No momento do debate, o professor media a discussão, ouvindo a síntese das pesquisas realizadas, a opinião dos alunos sobre o tema, relacionando sempre esse momento ao conto, trazendo para a roda de discussão as impressões dos alunos sobre a história, a sua experiência, as transformações que eles sentiram materializar em si mesmos. Essa etapa final, cabe destacar, é apenas uma sugestão possível, como a leitura do conto a partir das estratégias aqui abordadas, cabendo ao professor adaptá-la, modificá-la ou mesmo construir etapas distintas.

Procurou-se, dessa forma, orientar aqui uma prática guiada a partir de uma sequência em que, conjuntamente com a participação dos alunos, o professor pratica o ensino das estratégias de compreensão leitora necessárias para abordar e compreender o texto de literatura. Nesse processo, salienta-se que o objetivo é tornar transparente aos alunos o ato de leitura por eles realizado, evidenciando as estratégias acionadas e utilizadas na compreensão do texto e na construção de seus sentidos. Assim, o aluno leitor torna-se consciente do papel ativo que desempenha no ato de ler, interagindo e dialogando com o texto, ressignificando-o, atento para a materialidade e especificidade de sua linguagem. Esse processo, frisa-se, tem a intenção de edificar na escola a educação literária e a formação do leitor de literatura.

\section{CONSIDERAÇÕES FINAIS}

Nos últimos tempos, a formação do leitor de literatura tem sido um tema bastante debatido nas pesquisas sobre o fenômeno da leitura. Muitos são os espaços que contribuem para essa formação, no entanto, o espaço privilegiado para a aprendizagem, a descoberta e o exercício da leitura continua sendo a escola, portanto, é natural que os estudos tenham se centrado nesse espaço social; afinal, cabe à escola e professor a difícil tarefa de não apenas ensinar a ler, mas formar leitores. Nesse sentido, considerando a importância dessa formação leitora na escola, a presença do texto literário na sala de aula foi ressignificada. Se a literatura ainda se faz presente no ambiente escolar, é porque sua tessitura ficcional ou poética ajuda na complexa tarefa da formação do leitor.

A formação do leitor literário, por sua vez, exige um esforço criativo na construção de novos caminhos que levem o aluno a encontrar-se com o texto. Desse esforço nascem as práticas leitoras propostas e desenvolvidas na mediação de leitura, método cada vez 
mais defendido na escola. A presença da mediação de leitura e de professores mediadores na sala de aula faz-se necessária e urgente quando suas atividades têm por finalidade apresentar ao aluno o deleite, a fruição, o prazer, enfim, que advém da leitura literária. Práticas leitoras guiadas pelo prazer, certamente, podem funcionar como um convite a esse encontro entre alunos e literatura, porém, é preciso algo mais para que esse encontro, além de perdurar, se efetive. É partindo dessa reflexão que a formação do leitor de literatura deve ser pensada a partir do letramento literário, pois letrar literariamente torna o aluno consciente de que a literatura também é um uso social da linguagem, e que esta exige, assim, aprendizagem.

Nesse sentido, entende-se que é possível mediar e ensinar a leitura da literatura na escola, desenvolvendo o prazer e a aprendizagem. Mas esta, por sua vez, só ocorre quando a abordagem do texto de literatura é feita por meio de estratégias efetivas e sistematizadas que levem o aluno a compreender que a literatura se faz linguagem, e que são essas estratégias alternativas que ajudam a ensinar a ler literatura. Além disso, nessa atividade de leitura a partir das estratégias aqui analisadas, o processo de leitura tornou-se transparente ao aluno/ leitor, e este passa a compreender seu papel ativo nesse processo, entendendo o texto, construindo leituras possíveis em um diálogo dinâmico. O leitor compreende, assim, que ele pode interagir com o texto, ressignificando-o, sempre atento à sua materialidade linguística.

Deseja-se, assim, com este trabalho, traçar um caminho de reflexões e práticas para o docente trilhar, vislumbrando ser possível, sim, formar leitores de literatura na escola. Estes, por sua vez, poderão sair desse espaço munidos do conhecimento necessário para transitar em outros lugares, sejam reais ou virtuais, onde eles também se encontram com o texto de literatura. Almeja-se, em resumo, com este estudo, poder contribuir para promover o ensino da leitura literária na escola, com vistas à formação e desenvolvimento do leitor de literatura: leitor autônomo, competente, capaz de selecionar suas leituras, de produzir sentidos no diálogo com o texto, capaz de compreender igualmente a importância das estratégias adequadas a serem utilizadas na leitura do texto. 


\section{REFERÊNCIAS}

BARBOSA, B. T. Letramento Literário: sobre a formação escolar do leitor jovem. Educ. foco, Juiz de Fora, v. 16, n. 1, p. 145-167 mar/ago/2011.

COSSON, R; SOUZA, R. Letramento literário: uma proposta para a sala de aula. UNESP, agosto/2011. Disponível em: https://acervodigital.unesp.br/bitstream/123456789/40143 /1/01d16t08.pdf

COSSON, R. Letramento literário: teoria e prática. São Paulo: Contexto, 2016.

COSSON, R. O espaço da literatura na sala de aula. Coleção explorando o ensino da literatura. vol.20 Ensino Fundamental. Ministério da Educação. Brasília, 2010. Disponível: $<$ http://www.portaltrilhas.org.br/download/biblioteca/literaturainfantil.pdf\#page=55>.

COSSON, R. A prática da leitura literária na escola: mediação ou ensino? Nuances: estudos sobre educação. Presidente Prudente-SP, v. 26, n 3, p. 161-173, set/dez/2015. Disponível em:

GIROTTO, C.G. G. S; SOUZA, R. J. Estratégias de leitura: uma alternativa para o início da educação literária. Álabe 4, diciembre 2011. Disponível em: [http://www.ual.es/ alabe]

LIMA, L. E. C. Mediação da leitura e formação do leitor. In: NETO, R; LIMA, L. E. C. (Org.) Curso Formação de Mediadores de Leitura. Fortaleza, CE: Fundação Demócrito Rocha, 2018.

RODRIGUES, S. F. P. Estratégias de leitura - estado da arte. Educar em Revista. CuritibaPR, v. 34, n 72, p. 111-130, nov/dez/2018.

SILVA, A. A. M. O letramento literário através da leitura de "o pequeno príncipe". 2015. 83 f. Dissertação (Mestrado Profissional em Letras) - Universidade Federal de Pernambuco, Recife, PE, 2015.

SILVA, J.R. M. A leitura literária na sala de aula: estratégias de leitura e o processo de alfabetização. Revista Graphos. v. 21, n¹, p. 24-40, 2019.

VALARINI, S. D. Estratégias didático-metodológicas para o 'ensino' da leitura do textoliterário. In: Congresso Internacional de Leitura e Literatura Infantil e Juvenil. Porto Alegre -RS: Edipucrs, 2012. p. s/n-s/n. Disponível em: http://ebooks.pucrs.br/edipucrs/ anais/IIICILLIJ/Trabalhos/Trabalhos/S9/sharlene alarini.pdf

VIEIRA, H. F. S. C.. Letramento Literário - um caminho possível. Revista ArReDia. Dourados-MS, v. 4, n 7, p. 117-126, jul/dez/2015.

Enviado em: $\quad$ 07/12/2019

Aceite em: $\quad$ 18/12/2010 